\title{
LA MINERÍA DE LA SAL DURANTE EL SIGLO XX EN SAN PEDRo DE ATACAMA, Chile (II REgión): ENTRE LA EXPLOTACIÓN ARTESANAL Y LA INDUSTRIALIZACIÓN
}

\author{
Flora Vilches, ${ }^{1}$ Lorena Sanhueza, ${ }^{2}$ Cristina Garrido, ${ }^{3}$ Cecilia Sanhueza ${ }^{4}$ y Ulises Cárdenas ${ }^{5}$
}

\begin{abstract}
Durante el siglo XX, la explotación de sal en el oasis de San Pedro de Atacama formó parte del ciclo de expansión capitalista asociado a la gran industria de la minería del cobre, aunque también a otros usos menores. Si bien la documentación histórica sobre esta industria es muy escasa, contamos con los restos materiales asociados a ella y la memoria de quienes estuvieron involucrados en su explotación. En este artículo presentamos evidencia arqueológica de asentamientos con diferencias temporales, de escala y naturaleza de la explotación, cuestión que da cuenta de las distintas formas en que la población local y externa al oasis se relacionó con esta nueva estrategia de subsistencia. Discutimos las implicancias sociales de la coexistencia de una explotación artesanal e industrial para la población indígena local, en un oasis tan aislado como globalizado.
\end{abstract}

Palabras claves: minería de la sal - capitalismo - Atacama - arqueología industrial.

\begin{abstract}
During the zoth century, rock salt exploitation in the oases of San Pedro de Atacama was part of the capitalist expansion mainly associated with the great copper mining industry and to other minor uses. Historical documentation of these practices is scarce, although material remains and former actors in the mining process still survive. In this article we present archaeological evidence of rock salt mining sites of different temporality, scale and nature of exploitation. Such differences illustrate the distinct ways in which the local population and newcomers related to this new mode of subsistence. We discuss the social implications for the native indigenous population of the coexistence of artisan salt exploitation and industrialization within the context of an oasis both isolated and globalized.
\end{abstract}

Key words: salt mining - capitalism - Atacama - industrial archaeology.

\section{* Introducción}

La explotación de sal en el oasis de San Pedro de Atacama, al interior de la II Región de Antofagasta, Chile, formó parte del ciclo de expansión capitalista asociado a la gran industria de la minería del cobre, aunque también estuvo ligada a otras utilidades económicas - como el consumo alimenticio y la industria farmacéutica- y socioculturales -mediante relaciones de parentesco e intercambio simbólico de tradiciones-; pero también religiosas -a través de la incorporación de narrativas míticas y prácticas rituales- y políticas -instauración progresiva de nuevas instituciones y autoridades (Cárdenas 2006). Mientras Chuquicamata se transformaba en el gigante tecno-económico del país, los emprendimientos del interior eran de escala y alcance considerablemente menores. Esta falta de protagonismo de la industria de la sal explica que su documentación histórica sea muy reducida. Salvo los registros de inscripción de minas, sólo contamos con los restos materiales asociados a ellas y la memoria de quienes estuvieron involucrados en su explotación.

A partir del registro arqueológico, hemos logrado identificar una serie de asentamientos mineros en la cordillera de la Sal, sector que hoy forma parte de la Reserva Nacional Los Flamencos bajo la co-administración de la Corporación Nacional Forestal (CONAF) y la Asociación Indígena

Recibido: julio 2014. Aceptado: octubre 2014.

\footnotetext{
${ }^{1}$ Departamento de Antropología, Universidad de Chile. Av. Ignacio Carrera Pinto 1045, Ñuñoa, Santiago, CP 7800284, CHILE. Email: floravil@uchile.cl

2 Departamento de Antropología, Universidad de Chile. Av. Ignacio Carrera Pinto 1045, Ñuñoa, Santiago, CP 7800284, CHILE. Email: loresan@uchile.cl

3 Programa de Doctorado UTA-UCN. Av. 18 de Septiembre 2222, Casilla 6-D, Arica, CHILE. Email: cristina.garrido.contreras@gmail.com
} 


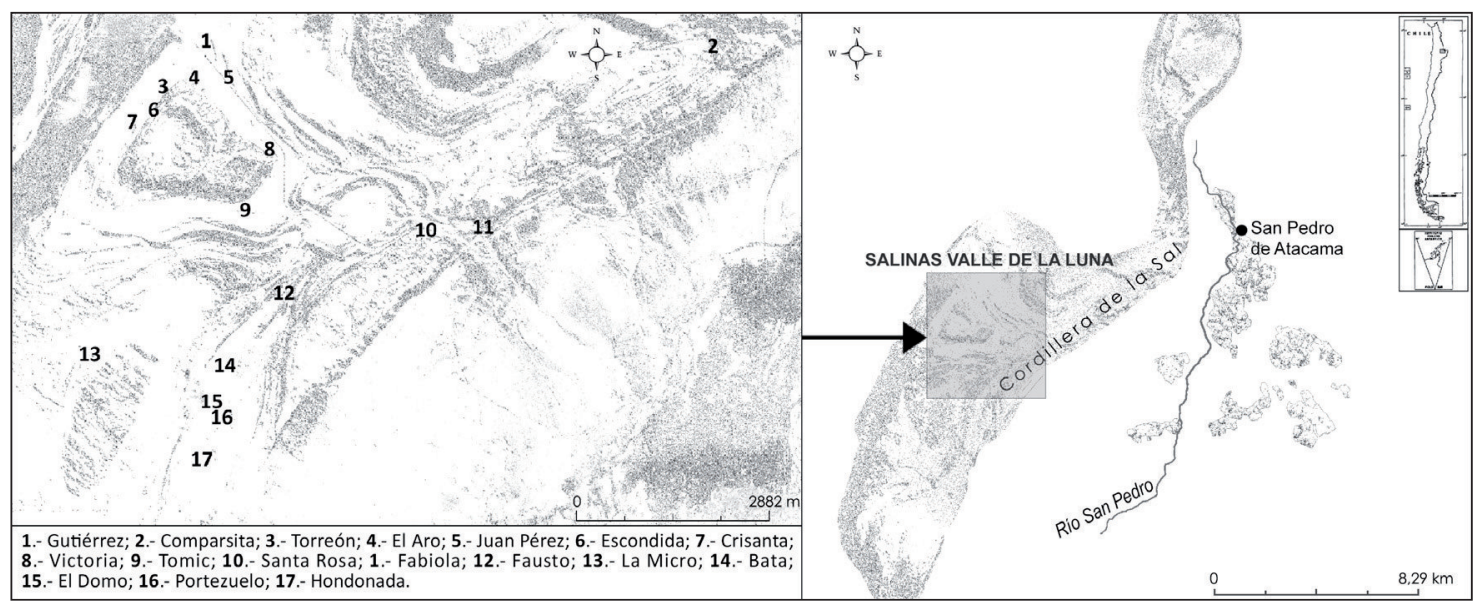

Figura 1. Mapa sector Salinas del Valle de la Luna, San Pedro de Atacama, con detalle de los asentamientos identificados. Dibujo: Paulina Chávez.

Valle de la Luna, ${ }^{6}$ en la vertiente oeste del oasis, a $6 \mathrm{~km}$ de San Pedro de Atacama (Figura 1). Los asentamientos se configuran a partir de una serie de elementos cuya combinatoria muestra diferencias temporales, de escala y naturaleza de la explotación, dando cuenta de un proceso capitalista heterogéneo que combina prácticas mineras protoindustriales o artesanales y de industrialización propiamente tales (Pinto y Ortega 1990). De acuerdo a los registros orales, documentales y de algunas materialidades, dichas explotaciones de sal se desarrollaron en dos momentos identificables dentro de la primera y segunda mitad del siglo XX.

El impacto marginal de la minería de la sal en los oasis de San Pedro de Atacama cabe dentro de un proceso de in-

\footnotetext{
4 Instituto de Investigaciones Arqueológicas y Museo R.P. Gustavo Le Paige s.j. (IIAM), Universidad Católica del Norte. Gustavo Le Paige 380, San Pedro de Atacama, CP 1410000, CHILE. Email: msanhueza@ucn.cl

5 Colegio de Antropólogos de Chile, A. G. David Arellano 1810, Independencia, Santiago, CP 8380039, CHILE. Email: ulises. cardenas@gmail.com

6 La Asociación Indígena Valle de la Luna fue creada el 2002 y agrupa a seis comunidades indígenas de San Pedro de Atacama (Coyo, Larache, Quitor, San Pedro, Sequitor y Solor) en relación de cotutela con el Estado en el resguardo, conservación y manejo del patrimonio natural y cultural de la localidad del que hace parte las Salinas del Valle de la Luna. Líderes en la administración turística de la reserva, han desarrollado una serie de estrategias y protocolos de acceso, incluyendo la perspectiva cultural licanantay por medio de la puesta en valor de prácticas e historias de vida asociadas a las familias atacameñas del período 1880 al 1980 en estudio.
}

dustrialización nacional de por sí liviano (Cavieres 1998). En ese contexto, nos parece de interés indagar en las implicancias sociales de esta actividad para la población del oasis tanto a nivel local como en el contexto global del fenómeno capitalista del cual se hizo parte. En este artículo discutimos la evidencia arqueológica prestando atención a los modos en que los sampedrinos han ido negociando el advenimiento de la modernidad mediante estrategias que muchas veces operan en los intersticios del capitalismo (véase Johnson 1996; Leone 1999).

\section{Capital e industria(lización) en San Pedro de Ata- cama: los albores del siglo XX}

Durante las últimas décadas del siglo XIX, la sociedad atacameña sufrió un cambio dramático en sus modos de subsistencia, transitando de una economía fundamentalmente agro-pastoril a una más diversificada con base capitalista (Núñez 2007 [1991]). El motor de dicha transformación fue la instalación de grandes industrias mineras en la región, tanto metálicas (Caracoles, Chuquicamata) como no metálicas (cantones salitreros El Toco y Pampa Central), superando notoriamente en producción, alcance, transacción y exportación a otras industrias mineras menores como el azufre y la sal. Mayoritariamente, la población indígena local afianzó la arriería como una de sus principales estrategias mercantiles para surtir de ganado y otros bienes a los enclaves mineros y, en menor medida, continuó intercambiando o comercializando dentro de sus circuitos tradicionales productos agropecuarios y de reco- 
lección (como algarrobo y chañar), incluyendo también cueros y lana de guanaco y vicuña, entre otros (Sanhueza y Gundermann 2007; Sanhueza 2012; Vilches et al. 2014).

A partir de la primera mitad del siglo XX, sin embargo, se registra un punto de inflexión en la incorporación de estrategias capitalistas en la población indígena campesina (Sanhueza y Gundermann 2007). Tras la crisis económica mundial que afectó la producción de salitre en 1929 , la demanda de ganado y de forraje para alimentarlo disminuyó notablemente, por lo que "remeseros" y "peones" dedicados a su traslado así como campesinos encargados de su engorde, debieron buscar nuevas fuentes de trabajo. Ello se vio reforzado posteriormente por la instalación del ferrocarril Salta-Antofagasta que, a partir de la década de 1940, absorbió gran parte del tráfico vacuno que había logrado sobrevivir, marginando a San Pedro de Atacama del lucrativo negocio ganadero. Este proceso implicó la migración creciente de un contingente importante de población atacameña hacia los centros urbano-industriales de Calama y Antofagasta donde se incorporó como fuerza de trabajo. No obstante, otro grupo de habitantes de los oasis mantuvo una base de subsistencia agropecuaria y a la vez incursionó en la explotación de yacimientos mineros, incluyendo el cloruro de sodio en la cordillera de la Sal, en las inmediaciones del pueblo de San Pedro de Atacama.

Cabe destacar que es justamente en esta época posterior a la crisis mundial, que el Estado chileno toma una serie de medidas proteccionistas en torno a la restricción del comercio exterior y la creación de créditos para la industria nacional con el fin de impulsar, o mejor dicho no detener, el desarrollo del sector industrial en el país. En efecto, varios economistas concuerdan en señalar que lo que ocurrió en el Chile de 1860 a 1920 no fue un proceso de industrialización precisamente, sino más bien el aprovechamiento de momentos coyunturales de mediana duración que permitieron crecimientos económicos importantes, pero sin continuidad en el tiempo (Carmagnani 1971; Pinto y Ortega 1990; Ortega 1991-1992; Cavieres 1998; De Vos 1999). Tras el boom del salitre, entonces, lo que permanece es "un grupo dirigente poderoso y ostentoso, un ámbito de la vida nacional en vías de modernización, pero una realidad social tradicional y carente de posibilidades reales" (Cavieres 1998: 17), cuya composición fue mayoritariamente extranjera o bien de chilenos provenientes de sectores coloniales medios o descendientes de extranjeros. Los gobiernos a partir de la década de 1930, buscaron alternativas a la mono exportación de productos primarios (salitre, cobre) y a la alta dependencia de productos importados hasta ese entonces imperante. El Estado redobló su protagonismo a través de una serie de medidas, dentro de las cuales destaca la creación de la Corporación de Fomento a la Producción (CORFO) en 1939, el Ministerio de Minería en 1953 y la Empresa Nacional de Minería (ENAMI) en 1960. La idea central de la política económica chilena fue lograr un país verdaderamente desarrollado, mediante un proceso real de industrialización capaz de sostenerse en el tiempo.

Si volvemos al contexto regional de San Pedro de Atacama, no cabe duda de que se replica la radiografía nacional recién señalada, aunque en menor escala y con distintos matices. El crecimiento industrial y urbano generado por la explotación del salitre y luego por la minería del cobre, provocó un fuerte aumento en la demanda por servicios públicos y por el acceso a recursos naturales indispensables para las operaciones productivas. En ese escenario el Estado chileno delegó en el sector privado la responsabilidad por la inversión en algunos servicios y facilitó las condiciones para satisfacer las demandas productivas de dicho mercado. Para ello recurrió, al menos desde la década de 1910, a la concesión de mercedes o de arrendamientos de aguas, tierras y recursos considerados fiscales, a particulares o empresas que así lo solicitaban. Si bien esto pudo favorecer a la pequeña y mediana industria, las comunidades agro-ganaderas indígenas de la región se vieron muy afectadas al ser despojadas de recursos vitales, especialmente en el caso de las comunidades de la zona del río Loa. Por su parte, las tierras indígenas de los oasis de San Pedro de Atacama comenzaron a ser adquiridas a través de la compra a pequeños o medianos propietarios y a concentrarse en manos de algunas familias de la élite local. A ésta última, de origen boliviano y argentino (como los Abaroa, Hoyos y De los Ríos, entre otras) se fue sumando un componente chileno representado por familias como los Polanco, de creciente importancia en el pueblo desde la ocupación militar de 1879 (Sanhueza y Gundermann 2007), así como de "austríacos" que emigraron al norte de Chile por motivos económicos y políticos (Zlatar 2002).7 Se podría

7 Cabe destacar que las familias de origen boliviano y argentino eran consideradas locales, pues su presencia en San Pedro de Atacama antecede la reconfiguración política del territorio atacameño tras 
decir que los primeros corresponden a una élite política y económica local, pese a que después de la Guerra del Pacífico devinieron en "foráneos", mientras que los segundos -tanto chilenos como inmigrantes- se asocian a "productivistas independientes" (Salazar y Pinto 1999) que se dedicaron principalmente al rubro comercial de las importaciones. Tal vez por su condición de élites, ambos grupos de empresarios comenzaron a relacionarse mediante lazos de parentesco, marcando una diferencia importante con los pobladores locales cuya inserción en este nuevo sistema fue como mano de obra o bien como pequeños productores agrícolas. ${ }^{8}$

En el contexto de la gran crisis económica de 1929, sectores rurales como San Pedro de Atacama no fueron incluidos en las prioridades regionales de desarrollo nacional. Sin embargo, considerando las condiciones capitalistas que los grupos de poder locales instauraron, cabe preguntarse: ¿Qué pasa en el oasis cuando las tierras agrícolas ya no producen capital? ¿Cómo se traduce en San Pedro el rol proteccionista más activo del Estado? ¿Qué rol juega la minería de la sal en este nuevo escenario? ¿Cómo se maneja la población indígena local en dicho contexto? Estas y otras preguntas son las que intentamos responder a partir de la interdigitación del registro arqueológico, oral y documental.

\section{Hacia una arqueología simétrica del capitalismo y la sal}

Considerando que la historia social y la antropología han obliterado la dimensión material del último siglo, no sólo en San Pedro de Atacama, sino que en Chile en general, resulta relevante el uso de la arqueología como medio para comprender los orígenes, desarrollo y condición del capitalismo, tal como lo han ejemplificado diversos au-

\footnotetext{
la Guerra del Pacífico. Con respecto a los "austríacos", se registran dos grandes oleadas migratorias de familias croatas a la ciudad de Antofagasta, una a fines del siglo XIX, y otra en las primeras dos décadas del siglo XX. Si bien se trataba de inmigrantes de nacionalidad croata, eran denominados "austríacos" por ser ciudadanos del Imperio Austro-Húngaro. Aquellos que arribaron al país con posterioridad a la Primera Guerra Mundial fueron llamados "yugoslavos" (véase Zlatar 2002; Zlatar y Ostojic 2006).

8 No existe en la actualidad evidencia de que algún atacameño en particular se haya enriquecido gracias a la producción de forraje (Vilches et al. 2014).
}

tores como Johnson (1996), Leone y Potter (1999), entre muchos otros. En efecto, si el capitalismo es entendido como un conjunto de relaciones sociales que suponen una fuerza de trabajo que vende su agencia para subsistir, desde fines del siglo XIX el sector de San Pedro de Atacama se ajusta a dicho modelo. Como ya lo hemos señalado, las comunidades indígenas se introdujeron en el nuevo sistema económico, primero como fuerza de trabajo en labores subsidiarias de la industria minera y, luego, como fuerza de trabajo en labores industriales propiamente tales y cada vez más diversificadas. El rol de la ideología (sensu Althusser en Leone 1985) es fundamental para entender los modos en que la población atacameña fue negociando el advenimiento de la modernidad que trajo consigo el capital. La misma conexión pasado-presente es una manifestación de la ideología, que en el caso del período de expansión capitalista habla de los intereses de una clase específica, sea social (poder económico), estatal (poder político) o académica (poder del conocimiento) (Foucault 1980; Leone 1999).

Enfrentarse a la arqueología del pasado contemporáneo es una tarea relativamente nueva. Si bien desde la década de 1960 la arqueología histórica se consolidó en países del hemisferio norte, el tratamiento específico del capitalismo anclado en el siglo XX es aún embrionario aunque poco a poco gana terreno en la academia (Buchli y Lucas 2001; Buchli 2000; Holtorf, C. y A. Piccini 2011; GonzálezRuibal 2006, 2007a; Harrison y Shofield 2010; Leone 1999; Vilches 2011). Tal como lo subraya González-Ruibal (2006), una de las ventajas de practicar una arqueología del presente es que puede contribuir sustancialmente a una "arqueología simétrica" (Witmore 2007a; González-Ruibal 2007b). En otras palabras, una arqueología simétrica del presente pretende contribuir a la arqueología y antropología en general, promoviendo una práctica más reflexiva, orientada a sobrepasar la dicotomía entre pasado/presente y la dualidad entre lo material e inmaterial. En ese sentido, se propone mapear las relaciones entre diferentes pasados que se permean en el presente mediante una "topografía" más que una cronología lineal (Witmore 2007b).

En este artículo, por lo tanto, proponemos agregar una visión arqueológica a la comprensión de la expansión capitalista en los oasis de San Pedro de Atacama a partir del estudio de la minería de la sal. La mirada arqueológica no sólo involucra aproximarnos al aspecto físico de 
los restos materiales asociados a esta industria, sino a la exploración de experiencias situadas en el seno de la vida material, la constitución del mundo objetual y, en definitiva, de su rol modelador de la experiencia (Meskell 2004). Bajo esta perspectiva, una arqueología de la expansión capitalista no pretende oponerse al trabajo de la antropología o de la historia sino todo lo contrario, apuesta a recuperar aquella "densidad material" del mundo que habitamos (Buchli y Lucas 2001) -en este caso el que habitaron los mineros de la sal- a través de herramientas arqueológicas, en un diálogo permanente con las herramientas de la antropología y la historia.

En este escenario, el estudio de los relatos orales y documentales como recurso de validación sociocultural, es tan importante como el mundo objetual, ya que permite examinar cómo las experiencias de encuentro con la dimensión material intervienen en las prácticas de elaboración y reconstrucción del pasado. Por ello, no es posible concebir la práctica arqueológica sin un trabajo mancomunado entre especialistas de diversas disciplinas, pero también con la comunidad local, el cual nos permite ir proponiendo una topografía del período de expansión capitalista en la zona. Parte de dicha topografía se revela en este artículo cuando indistintamente interpelamos a los habitantes de la localidad en relación con nuestras diferencias disciplinarias. Es así que la noción de "sampedrino" surge de nuestros compañeros de trabajo atacameños; aquella de "población local indígena", se sitúa en un contexto de análisis demográfico y condiciones de habitabilidad del sujeto durante la época de la sal; mientras que "sociedad atacameña", surge del análisis diacrónico de los datos y, "población atacameña", hace parte de las conclusiones analíticas propias de la arqueología situacional, cuando fija la mirada en un período específico de productividad. Es tan sólo un ejemplo de la tarea que hemos emprendido para comenzar a hilvanar los pliegues de un pasado-presente en torno a la explotación de sal y que exponemos a continuación.

\section{* Las salinas del Valle de la luna}

Durante nuestra primera etapa de investigación documental, los archivos del Fondo de Conservadores de Bienes Raíces El Loa (FCBR) revelaron un activo aunque oscilante registro de manifestaciones de yacimientos de cloruro de sodio en la Cordillera de la Sal durante el siglo
XX. Sin embargo, por su naturaleza, este tipo de fuente presentaba una información valiosa pero muy general puesto que no permitía identificar geográficamente los yacimientos, como tampoco era indicativa de que su aprobación definitiva y su explotación se hubiera llevado finalmente a cabo. ${ }^{9}$ En ese contexto, y con la ayuda de información cartográfica y geosatelital, así como del relato de habitantes de la localidad, fuimos guiados a los sectores de minas donde realizamos una prospección pedestre. Nuestro objetivo fue registrar los asentamientos asociados a la explotación de sal de modo de caracterizarlos sobre la base de su espacialidad y materiales asociados, con el fin de comprender más específicamente los matices no sólo tecnológicos sino sociales de esta estrategia de subsistencia en San Pedro de Atacama a lo largo del siglo XX.

Como resultado se identificaron 17 "asentamientos mineros" asociados a minas de sal (Figura 1), que se configuran a partir de tres elementos: una o más estructuras arquitectónicas, las plataformas de acopio y carga del material a camiones, y el área de extracción. ${ }^{10}$ A éstos se asocian basurales discretos o bien basuras dispersas que por las condiciones climáticas del sector (extrema sequedad, alta oscilación térmica y lluvias torrenciales ocasionales) y la naturaleza del sustrato salino, se encuentran "petrificadas" en una costra de sal. Dicha situación impide levantar los restos sin destruirlos ya que, además, presentan un proceso de meteorización importante producto de la naturaleza corrosiva de la sal.

9 La "manifestación" es una figura legal mediante la cual una persona natural o jurídica solicita un sector de interés con el objetivo de explotar minerales. No obstante, para que este trámite se materialice en una concesión minera, requiere de un largo procedimiento que incluye la aprobación del correspondiente Juzgado de Letras, el pago de un impuesto, la mensura y delimitación geográfica del yacimiento y su posterior publicación oficial.

${ }^{10}$ De estos 17 sitios, nueve fueron identificados por habitantes locales (Comparcita, Fabiola, Santa Rosa, Gutiérrez, Fausto, Tomic, Victoria, La Micro, Crisanta). De esos nueve, sólo tres nombres coincidían con aquellos que aparecen en la documentación del FCBR (Fabiola, Victoria y Crisanta). Los ocho sitios restantes fueron identificados en nuestras prospecciones y sus nombres responden a nomenclaturas creadas por nosotros (también los nombres Tomic y La Micro fueron creados por el equipo puesto que las personas que las identificaron no las asociaron a nombres específicos). Bien puede que existan más minas de las que registramos y estén sepultadas por aluviones, como es el caso de Comparcita. 
Con respecto al componente arquitectónico de los asentamientos, se aprecian dos modalidades constructivas bastante diferenciadas. La primera consta de estructuras levantadas a partir de bloques de sal, generalmente canteados, dispuestos uno encima del otro, mayormente de manera orgánica, con o sin mortero. Así, se registran recintos de hasta $100 \mathrm{~m}^{2}$, con muros entre dos y tres metros de alto. Los techos son a una o dos aguas, en algunos casos con vigas de algarrobo y brea (Figura 2) o bien de calamina. La segunda modalidad arquitectónica que se advierte es una totalmente desmantelable, a partir de estructuras de madera forradas con pizarreño, latas y/o calamina. Un buen ejemplo de esto es el sitio "Tomic", donde tan sólo queda la impronta de una estructura subdividida en tres espacios. Es probable que este tipo de arquitectura también haya estado presente en otros sitios que no presentan arquitectura en bloques de sal, aunque no pudimos identificarlas. Asimismo, se trata de materiales constructivos con altas posibilidades de reutilización, de hecho en la mayoría de los sitios fueron retirados del lugar una vez finalizada la explotación de la mina. Tal es el caso del techo de la mina Santa Rosa, cuyas planchas de calamina hoy forman parte del cierre perimetral de la casa de su dueño, en el pueblo de San Pedro de Atacama (Figura 3).

Las plataformas de acopio y carga corresponden a pequeños muros de bloques de sal que afirman un aterrazamiento del cerro donde se acumulaba la producción de sal, y donde ésta podía cargarse en el camión que la trasladaría a otro lugar para ser procesada y/o distribuida. Las áreas

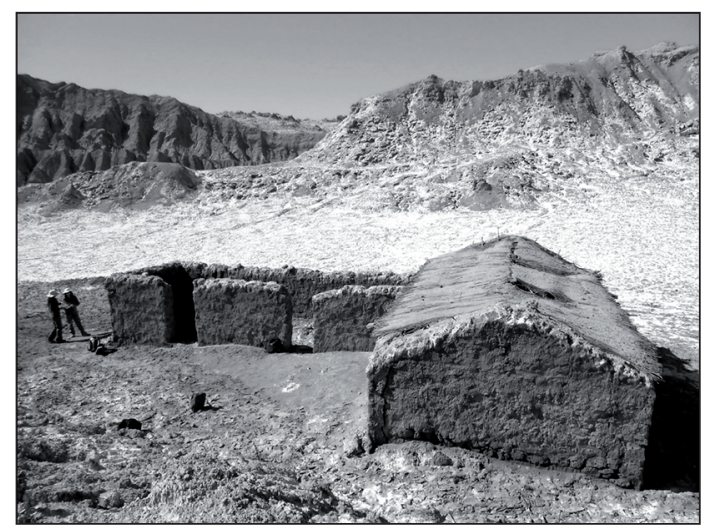

Figura 2. Asentamiento "Fausto", sector habitacional con estructura de sal y techo a dos aguas. de extracción, por su parte, son de tres tipos. El primero corresponde a una explotación "aérea", en que la extracción va socavando el cerro donde se encuentra la veta de forma horizontal. El segundo refiere a una explotación "subterránea", pues la extracción socava la veta bajo el nivel superficial. Y el tercero - de extracción también subterránea-, implica la ejecución de verdaderos "piques" mineros, cuya explotación reviste mayor complejidad para alcanzar su fondo. Los tres tipos requerían el uso de explosivos, tal como lo atestiguan las numerosas mechas que se encuentran en superficie o las improntas de tiros en las paredes de sal.

Las basuras asociadas a estos asentamientos mineros son básicamente de dos tipos: vivienda/alimentación y extracción. El primer grupo está representado por restos materiales que aluden a la construcción o a partes de viviendas, basuras asociadas a actividades cotidianas, vestimentas, artículos de aseo personal y, muy abundantemente, restos de alimentación, tanto frescos como envasados, y bebestibles. La segunda categoría está referida a las materialidades relacionadas con la extracción y transporte de la sal propiamente tal, así como vestimenta asociada a los trabajadores.

Junto con los asentamientos, identificamos 14 "puntos de extracción", los que corresponden a "piques" aéreos o subterráneos asociados a plataformas, no así a estructuras, y presentan escasa basura dispersa. Están localizados en proximidad a minas grandes, por lo que su explotación podría haber estado ligada a ellas.

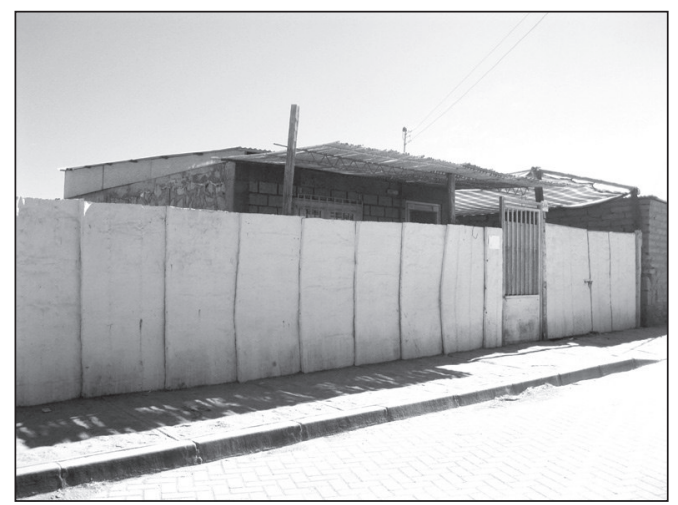

Figura 3. Vivienda en San Pedro de Atacama cuyas latas - que conforman el muro que cierra la casa- fueron parte del asentamiento "Santa Rosa". 
La minería de la sal durante el siglo xx en San Pedro de Atacama, Chile (ii región): ENTRE LA EXPLOTACIÓN ARTESANAL Y LA INDUSTRIALIZACIÓN

\begin{tabular}{|c|c|c|c|c|c|c|c|c|c|}
\hline SITIO & recintos & $\begin{array}{c}\mathbf{m}^{2} \\
\text { construidos }\end{array}$ & $\begin{array}{c}\mathrm{m}^{3} \\
\text { extracción }\end{array}$ & $\begin{array}{c}\text { extracción } \\
\text { aérea }\end{array}$ & $\begin{array}{l}\text { extracción } \\
\text { profunda }\end{array}$ & piques & plataformas & rampas & $\begin{array}{c}\text { áreas de } \\
\text { acopio }\end{array}$ \\
\hline Comparcita & $s / i$ & & $s / i$ & & & & & & \\
\hline Fabiola & $\mathrm{s} / \mathrm{i}$ & & 981 & 2 & & - & ? & & \\
\hline \multicolumn{10}{|c|}{ EXPLORATORIOS } \\
\hline Juan Pérez & 1 & 6,5 & 114 & 1 & & - & & & \\
\hline Bata & 2 & 12,6 & 72 & 4 & & - & - & & \\
\hline Portezuelo & 1 & 23,4 & 38 & 1 & & - & 1 & & \\
\hline \multicolumn{10}{|c|}{ PEQUEÑOS } \\
\hline Torreón & 1 & 17,2 & 150 & 1 & & 1 & & & \\
\hline El Domo & 2 & 32 & 201 & 4 & & - & & & \\
\hline Santa Rosa & 1 & 36,8 & 195 & 3 & & - & 1 & 1 & \\
\hline El Aro & & & 225 & & & 1 & - & & \\
\hline \multicolumn{10}{|c|}{ MEDIANOS } \\
\hline Gutiérrez & 2 & 85,8 & $s / i$ & - & & 1 & $?$ & & \\
\hline Fausto & $3(4)$ & 86,6 & 2150 & 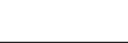 & $1 \mathrm{~A}, \mathrm{~B}, \mathrm{C}$ & 3 & 4 & 1 & \\
\hline Hondonada & - & & 1734 & 2 & & - & $?$ & & \\
\hline Escondida & - & & 3600 & 2 & & & & & \\
\hline \multicolumn{10}{|l|}{ GRANDES } \\
\hline Tomic & 1 & 33,6 & 5000 & 3 & & - & 1 & & 1 \\
\hline Victoria & 9 & 174,7 & 5816 & 12 & & 1 & 16 & & \\
\hline La Micro & - & & $\mathrm{s} / \mathrm{i}$ & 2 & & - & & & $\begin{array}{l}\text { "piscina" } \\
\text { decant. }\end{array}$ \\
\hline \multicolumn{10}{|c|}{ INDUSTRIAS } \\
\hline Crisanta & 5 & 234 & 8500 & & $\begin{array}{l}14+1 \text { con } \\
\text { trinchera }\end{array}$ & 2 & 13 & $\begin{array}{c}1(+ \\
\text { trinchera) }\end{array}$ & 8 \\
\hline
\end{tabular}

Tabla 1. Asentamientos mineros según jerarquía de explotación.

\section{Distintos modos de hacer}

Las características de cada uno de los asentamientos registrados pone en evidencia la existencia de diferencias temporales, de escala y naturaleza de la explotación, lo que ha permitido distinguir cinco conjuntos que abarcan explotaciones de carácter artesanal hasta propiamente industrial (Tabla 1):

a) Explotaciones exploratorias (Juan Pérez, Bata, Portezuelo). Corresponden a asentamientos cuyos recintos arqui- tectónicos, aunque construidos en sal, son de naturaleza expeditiva, a partir de bloques no canteados, de formas irregulares, pequeños y de muros bajos (Figura 4). Tienen escasa basura (de ambos tipos) y se asocian a áreas de extracción aérea.

b) Explotaciones pequeñas (Torreón, El Domo, El Aro y Santa Rosa). Tienen uno o dos recintos formalizados, de hasta $37 \mathrm{~m}^{2}$. Su arquitectura está hecha en base a bloques canteados con traba en los vértices, aunque sin mortero. El alto de los muros supera los $150 \mathrm{~cm}$. Están asociados a 


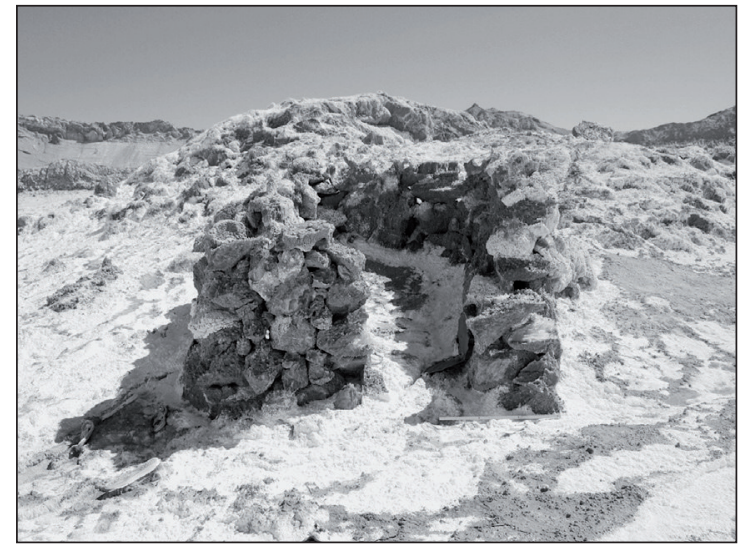

Figura 4. Asentamiento exploratorio "Bata”, vista general.

áreas de extracción sobre suelo (El Domo, Torreón y Santa Rosa) y de "piques" (Torreón y El Aro), presentando una o más plataformas de carga. La basura está dispersa y se compone tanto de basuras domésticas como asociadas a la extracción.

c) Explotaciones de mediana escala (Gutiérrez, Fausto, Hondonada y Escondida): presentan uno a tres recintos, algunos con subdivisiones, que llegan hasta los $85 \mathrm{~m}^{2}$ construidos. En Hondonada y Escondida no se registraron recintos, pero presentan basura ligada a actividades de vivienda/alimentación. Están asociados a basurales discretos y Hondonada presenta numerosa basura relacionada con el trabajo de extracción. Las áreas de extracción pueden ser de ambos tipos (Gutiérrez y Fausto presentan "piques").

\section{d) Explotaciones de gran escala (Victoria, Tomic y La Micro).} Los tres sitios que conforman esta categoría son de naturaleza distinta. Uno solo -Victoria- presenta recintos $(\mathrm{n}=7)$ que cubren una superficie construida de $174 \mathrm{~m}^{2} \mathrm{y}$ responden a distintas funcionalidades: habitaciones, posible área administrativa, baño, bodega y cocina. Están asociados a numerosas áreas de extracción, una de ellas subterránea, mientras que la basura es abundante y refiere tanto a habitación/vivienda como a la actividad de extracción. El sitio Tomic tiene evidencias de arquitectura desmantelable, de la cual sólo sobrevive la impronta de una estructura, con abundante basura de vivienda y actividad de extracción ya sea dispersa o en basurales discretos. La Micro, por su parte, presenta menores evidencias de vivienda, pero sí abundantemente de extracción, aso-

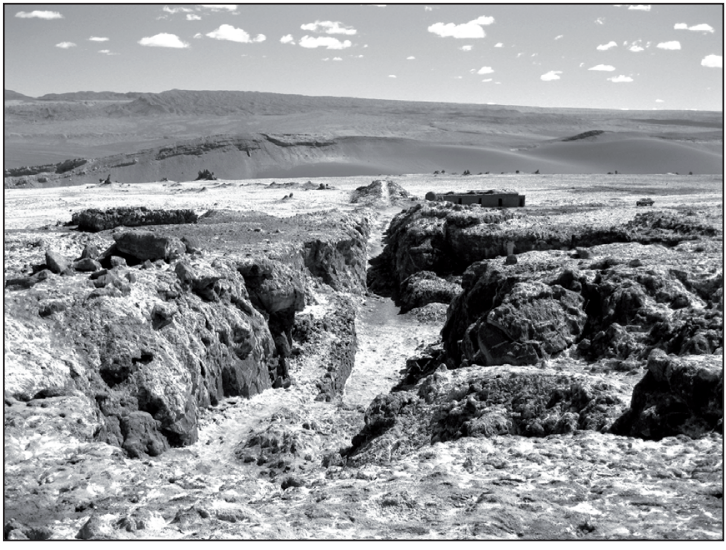

Figura 5. Asentamiento "Crisanta"; sector de extracción desde "tajo abierto" hacia plataforma de carga.

ciada a una instalación para el procesamiento intermedio de la sal (piscina de decantación), única en el registro.

e) Explotaciones industriales. Está representada por un solo asentamiento: la mina Crisanta. Cuenta con varios recintos que suman $234 \mathrm{~m}^{2}$ construidos y diferenciados funcionalmente: galpón habitacional, sala de máquinas y posibles bodegas, entre otros. El patrón arquitectónico sigue la construcción en sal, pero destaca el alto de los muros, que llega a los $3 \mathrm{~m}$, algunos de los cuales presentan revoque interior. El sector habitacional sigue el patrón industrial observado en campamentos salitreros y de azufre, formado por un solo cuerpo subdividido en cuatro "habitaciones", a la que se suma una cocina. El área de extracción de este campamento destaca por su tamaño y complejidad, separándolo notoriamente del resto de los asentamientos. Se trata de dos "piques" profundos que habrían conducido a un sistema de galerías subterráneas de al menos $30 \mathrm{~m}$, y un sector que asemeja una mina "a tajo abierto". Esta última se conecta con una larga y angosta plataforma de carga por donde corría un carro sobre rieles para la evacuación del mineral (Figura 5).

\section{La propiedad: atacameños y afuerinos; pirquineros y empresarios}

Durante la segunda etapa de revisión de la documentación del Fondo de Conservadores de Bienes Raíces El Loa (Calama) pudimos distinguir y sistematizar dos tipos de documentos que aportaron información de interés: las ya mencionadas "manifestaciones" mineras y los "registros 
de propiedad" ${ }^{\prime \prime 1}$. Si bien las primeras presentan la dificultad de ser ambiguas geográficamente y no permiten asegurar que el procedimiento legal posterior se llegó a concretar, son una valiosa herramienta para auscultar el interés que concitó este tipo de explotación. En efecto, entre 1933 y 1981 se registraron 45 manifestaciones relativas a vetas de cloruro de sodio ubicadas en la Cordillera de la Sal. ${ }^{12}$ Sin embargo, la cantidad de solicitudes presenta variaciones en el tiempo, lo cual permite identificar un primer momento de flujo entre 1933 y 1937, con 15 manifestaciones. ${ }^{13}$ Estas últimas involucran a empresarios chilenos y extranjeros identificados como "industriales", "comerciantes" y en menor medida "empleados", que declaran su domicilio en Calama o Antofagasta y aparentemente no están vinculados directamente con San Pedro de Atacama. Tras un hiato de poco más de 20 años, las manifestaciones reaparecen con fuerza el año 1960 redoblándose a 29. Esta vez corresponden a personas domiciliadas en Calama, pero también a habitantes de San Pedro de Atacama. ${ }^{14}$ Junto a "industriales" y "comercian-

${ }^{11}$ El Fondo de Conservadores de Calama se inicia en 1925, un año después de la creación del Departamento de El Loa. Por lo tanto, las inscripciones anteriores a esa fecha debieron realizarse en la ciudad de Antofagasta y no se incluyen en este trabajo.

12 Aparte de la sal, se registran durante ese mismo período manifestaciones de otro tipo de minerales tales como azufre, plata, plomo, ramasodio, estaño, arcilla, cobre, oro, sílice, hierro, mármol, ónix, travertino, creta, manganeso y fierro, ubicados en distintos sectores de los alrededores de San Pedro de Atacama. Estas solicitudes fueron efectuadas por personas foráneas, por habitantes de San Pedro de Atacama (especialmente por familias de importante influencia y trayectoria histórica en el oasis), y en menor medida por grupos familiares indígenas.

${ }^{13}$ Es importante considerar que estas primeras manifestaciones mencionan entre sus límites a otras concesiones ya formalizadas, lo que revela que el proceso de inscripción de yacimientos de sal había comenzado con anterioridad a la creación del Registro de Conservadores de Bienes Raíces en Calama (FCBR, vol. $28 n^{\circ} 64$, 152, 270, 275).

${ }^{14}$ Es posible que varios de estos casos correspondan a personas que, siendo habitantes de San Pedro de Atacama, aparecen registradas con domicilio comercial en Calama, práctica común hasta nuestros días. En general, este patrón de "doble residencia" o "doble domicilio" ha caracterizado a los habitantes de ésta y otras regiones andinas desde tiempos pretéritos, aplicándose también en actividades tradicionales vinculadas al pastoreo u otros rubros productivos como la caza y recolección que requieren de la presencia estacional en lugares alejados del pueblo de origen. En la actualidad es frecuente que grupos familiares de los oasis de San Pedro de Atacama posean también una propiedad en tes", aparecen las categorías "minero" y "agricultor", así como las primeras solicitudes realizadas por mujeres. Sólo algunos propietarios trascienden ambos momentos: Esteban Tomic (luego denominada Sucesión Esteban Tomic Dvornik, Sucesión Esteban Tomic Romero, Propiedad Minera Tomic Hermanos) y Modesto Escalante Zuleta (luego Sucesión Modesto Escalante), que se configuran como los dos grandes empresarios de la sal.

Si cotejamos las manifestaciones o solicitudes con los registros de propiedad definitivos, es decir con aquellos documentos que incluyen las respectivas actas de mensura, podemos notar que estas últimas representan una cantidad drásticamente menor a las manifestaciones originalmente solicitadas y no se distribuyen en el tiempo marcando los grandes vacíos señalados. Esto parece deberse más bien a un tema administrativo ya que el período de tiempo transcurrido entre la manifestación inicial y la mensura podía ser muy relativo, tardando desde un año entre una y otra, hasta incluso más de seis años. Destacan en los registros de propiedad y actas de mensura las familias Tomic (en 1937 mensura de minas "Rescatada" y "Recuperada", de 50 ha cada una, más pago de patente de otras propiedades anteriores); Escalante (mina Crisanta, 500 ha, manifestada en 1947 y otorgada en 1952), Olmos y Aguilar (Nueva Esperanza 50 ha, manifestada en 1960 y otorgada en 1961), Aguilar y Copa (mina Victoria, 300 ha, manifestada en 1971 y otorgada en 1977) (FCBR, vol. 151, n 35, año 1971 y vol. 178, s/n, año 1977).

De esta información documental, por otra parte, surgen varios temas de interés en torno a la propiedad, no sólo de las minas (quiénes eran sus dueños, de dónde provenían y a qué se dedicaban) sino también de la propiedad de la sal como recurso - no necesariamente económico- $y$, en definitiva, de la propiedad del territorio atacameño. Estas interrogantes adquieren mayor significación y complejidad cuando las

Calama, puesto que la ciudad ofrece servicios públicos y privados con los que no se cuenta en los pueblos del interior. En ese sentido, la residencia en Calama (sea más o menos transitoria) facilita el establecimiento de redes laborales, comerciales o industriales; oferta de trabajo y acceso a mano de obra; realización de trámites legales (permisos, patentes, etc.) como también la solución de necesidades hoy consideradas prioritarias como la educación de los hijos (ver González y Gavilán 1990; Jurado 2013). 
contrastamos con la información arqueológica y los testimonios de habitantes actuales de San Pedro. ${ }^{15}$

En primer lugar, el relato oral confirma que Modesto Escalante y Esteban Tomic (tanto padre -Tomic Dvornik- como hijo -Tomic Romero-) fueron los dos grandes empresarios ligados a la minería de la sal. Versiones contrastantes de nuestros entrevistados asocian a Escalante con las minas Fausto y Crisanta, así como a Tomic con Crisanta. Resulta de interés que Fausto no figura en las inscripciones revisadas, por lo que es muy posible que haya sido manifestada y otorgada en una fecha anterior a 1925, escapando a los archivos de Conservadores de El Loa. Crisanta, por el contrario, aparece manifestada por Escalante en 1947 y otorgada al mismo en 1952, por lo que la asociación que algunas personas hacen de esta mina con la familia Tomic, puede deberse a una venta posterior. ${ }^{16}$ De acuerdo a las características de ambos asentamientos, Crisanta coincide con aquél que alcanza el mayor nivel de industrialización en el sector. Fausto, en cambio, se ubica en una categoría mediana, pero al igual que Crisanta, presenta restos materiales que apuntan a que fueron ocupados durante la primera y segunda mitad del siglo XX (ver más abajo), apoyando la presencia contínua de ambos empresarios en el rubro de la sal.

Pero antes de adentrarnos en el tipo de minería que desarrollaron estos sujetos, es necesario reparar en que tanto Tomic como Escalante no pertenecen a las familias poderosas tradicionales de la localidad, que estuvieron asociadas al comercio de alfalfa y de ganado trasandino en décadas anteriores. ${ }^{17}$ Tampoco figuran en los regis-

${ }^{15}$ Las referencias a relatos orales de actuales habitantes de San Pedro de Atacama, corresponden a un total de 20 entrevistas realizadas entre los años 2006 y 2014.

${ }^{16}$ Cabe señalar que el sitio que nosotros identificamos como Tomic corresponde a otro asentamiento de menor envergadura que Crisanta, pero cuyo propietario era también Tomic, según testimonios de ex mineros.

17 Si bien una manifestación de 1933 menciona pertenencias de cloruro de sodio de Juan Abaroa Rodríguez en la cordillera de la Sal (FCBR, vol. 28 n 294), los archivos muestran una mayor inclinación de las familias de la élite boliviana, argentina y chilena (Abaroa, Polanco, Cerruti, De los Ríos, Carrazana, entre otras) a la explotación de otro tipo de minerales como plata y plomo (FCBR, 1926, vol. 6 n $365,366,367$ y 368). Por su parte, las familias Yutronic e Ivanovic (y mezclas de ambas) aparecen ligadas a pertenencias de azufre, en las décadas de 1940, 1950 y 1980 tros como asentados en San Pedro de Atacama sino en Calama, cuestión que hace pensar que controlaban una parte importante del proceso productivo desde ese lugar, delegando tareas en administradores alojados en el interior $y / o$ manteniendo una doble residencia. En ese contexto, es probable que las relaciones de intercambio surgidas durante la época de las remesas, sumadas a la diversificación en la conformación de redes de comunicaciones y de parentesco, hayan promovido el surgimiento -o reconfiguración, mejor dicho- de esta nueva "élite" que manejaba el "capital minero" con posterioridad a la gran crisis económica.

En efecto, Esteban Tomic Dvornik formaba parte del grupo de inmigrantes croatas que arribó a Chile en1899, asentándose en Calama, donde dejó de manifiesto su influencia al figurar como industrial asociado a la producción de sal gema (de mesa), además de ser el representante de la Esso Standard Oil, subagente de la General Motors, fundador del primer criadero de chinchillas en Chile, y propietario agrícola y de bienes raíces urbanos (Anónimo 1970, Mataic 1998). ${ }^{18}$ Su hijo, Esteban Tomic Romero, además de administrar y continuar los negocios de la sal de su padre, quien falleció a fines de la década de 1950, fue Gobernador del Departamento de El Loa durante el gobierno de González Videla y, pocos años más tarde, alcalde de Calama (Mataic 1998). Respecto a Modesto Escalante, si bien desconocemos su origen, sabemos que residió o estuvo vinculado buena parte de su vida a San Pedro de Atacama, puesto que figura postulando al cargo de Juez de Distrito en 1922 y como miembro de la junta de vecinos del pueblo en 1923 (FIA vols. 22, núms. 2 y 24, s/n). Este tipo de cargos era designado por las autoridades regionales o de Calama y se destinaba a los vecinos y propietarios más pudientes, que usualmente no eran de origen indígena (Sanhueza y Gundermann 2007). En la actualidad surgen discordancias entre algunos de sus descendientes en cuanto a su origen y filiación. Algunos lo ligan, por línea materna, al apellido Zuleta de Toconao; otros afirman que era originario de San Pedro de Atacama. En ambos casos, es

(FCBR, v. 55 n 20; v. 69 n $^{\circ} 13$ y 14; v. 190 n $^{\circ}$ 59, respectivamente).

18 Registros documentales indican que una planta de procesamiento de sal pertenecía, a lo menos desde 1927, a la familia Tomic (FIA, v. 51 n 1776). Según el relato oral era la única fábrica de sal gema en Calama. 
recordado como un sujeto progresista que trajo una serie de adelantos que significaron fuentes de trabajo en la explotación minera, la construcción de caminos y comercio en general. Sus empleados incluían atacameños de San Pedro de Atacama (aparentemente mediados por lazos de parentesco), pero también a afuerinos como el propio Esteban Tomic. Este último dicen que fue su contratista y más tarde su socio, hasta fines de la década de 1950, cuando fallece Escalante. El recuerdo destaca un incidente protagonizado por familiares de don Modesto, quienes continuaron con sus negocios, aunque no por mucho tiempo. En palabras de sus nietos:

"[...] se dejó de explotar la mina como familia [Escalante], porque ya no estaban los medios, no habia camiones, nos dimos vuelta. O sea él antes de fallecer se compró un Mercedes Benz, que era la única persona que tenía un Mercedes Benz. [...] nos dimos vuelta, se perdió el camión, todo al final. Él falleció y se vino abajo todo..." (Teresa Valdés Escalante, 2006).

"[...] mi abuelo Modesto falleció en Tocopilla; mi papá se llamaba Gustavo Escalante y él fue el que murió en ese accidente el 58. El camión era de don Paulino Ibáñez, quien también murió con Luciano Cruz, el que manejaba el camión..., murieron todos, yo era chico, tenía como seis años cuando eso pasó [...], siguieron trabajando en las minas, pero poco tiempo después, no me recuerdo bien, después que murió mi papá las cosas ya no eran como antes" (Roberto Escalante Pistán, 2014).

Las escasas manifestaciones mineras efectuadas en el mencionado lapso entre 1937 y 1960 , podrían entenderse en el contexto de un período en que el mercado de la sal era lo suficientemente reducido como para que lo abarcara Escalante por sí solo, en el entendido de que trabajara conjuntamente con Tomic, fuera este último su contratista y/o socio. ${ }^{19}$ Asimismo, es probable que los intereses de los grandes mineros/empresarios de la época se hayan dirigido con mayor fuerza a las actividades cupríferas, azufreras y borateras, sin generar mayor competencia.

Tras la muerte de Escalante y de Esteban Tomic padre, Esteban Tomic Romero se convierte en el mayor produc-

19 Ya en 1937, existe registro de una cesión de pertenencia minera de cloruro de sodio por parte de Modesto Escalante a Esteban Tomic Romero (FCBR, vol. 43, n 93 ). Presumimos que algo similar puede haber ocurrido con la mina Crisanta. tor de sal, llegando incluso a comprar la producción de los pequeños mineros de la zona. Su comercialización se expandió considerablemente, distribuyendo sal industrial para la empresa de explosivos Dupont y al mineral de Chuquicamata, además de vender sal gema a casas comerciales de Calama, Chuquicamata, María Elena, Tocopilla y Antofagasta. Sus ex empleados recuerdan que trabajaban a sueldo bajo un sistema de turnos que incluían obreros de San Pedro y también de Calama. Alojaban en el campamento habitacional y la administración les proporcionaba alimentación, para lo cual se mantenía un servicio de cocina. Todo ello es congruente con el registro arqueológico, pues Crisanta no sólo es el asentamiento con mayor volumen de extracción apoyado por una tecnología ad hoc, sino que además su configuración espacial responde a un patrón más clásico de campamento minero, con dependencias comunes de socialización y un sector extractivo separado, aunque con recintos que bien pudieron ejercer funciones de control.

No obstante, pese al monopolio indiscutible que la familia Tomic ejerció en el mercado de sal regional en la segunda mitad del siglo XX, es el momento en que las manifestaciones de cloruro de sodio reaparecen, aumentan y se diversifican, extendiéndose a familias locales de San Pedro de Atacama. Esto hace pensar que el mercado de la sal crece, cuestión que podría estar motivando a que grupos familiares de origen atacameño (Aguilar, Copa, Barboza, Aramayo, etc.) inscribieran y legalizaran vetas de sal que, posiblemente, explotaban desde tiempos más antiguos para su autoabastecimiento y comercio a pequeña escala. $\mathrm{O}$ bien, que las fuentes de subsistencia agropecuarias fueran cada vez más insuficientes, obligándolos a buscar alternativas en caso de que quisieran permanecer en el oasis en vez de emigrar a centros urbano-mineros. Tampoco sabemos hasta qué punto el apoyo que el Estado comienza a brindar a pequeños empresarios a través de la ENAMI, incidió en la mayor participación de familias atacameñas en la minería de la sal. Sea cual fuere el caso, lo interesante es que de todos los mineros/empresarios de este segundo período, hay uno que sobresale: Gabino Aguilar, atacameño y propietario de la mina Victoria. ${ }^{20}$

${ }^{20}$ Según los registros consultados, don Gabino Félix Aguilar Aguilar realiza en 1971 la inscripción de la pertenencia Victoria junto con Juan Copa Cruz y Juan Andrés Aguilar Aguilar (FCBR, vol. 
El recuerdo de la gente sindica a Gabino Aguilar como un empleador de varias personas en el proceso de extracción de la sal, así como ingenioso a la hora de implementar tecnologías que maximizaran el trabajo minero:

\section{“[...] él traía la sal, salía a vender, también cambiaba con leña pa'} llevar pa' los mineros, también con dinero, como quiera... así era. ...ése [Gabino Aguilar], tenía... tenía más cabeza pu, así que se hizo un molino, y con el mismo auto o sea camión, tenía camión él, un camioncito de roda [sic] entonces con la rueda del camión le daba vuelta a la polea y trabajaba el molino, un molino chiquito. Pero ése trabajaba la pura sal buena no más y pa' hallar las vetas de sal son angostitas pu, son así no más..." (Fermín Bautista, 2006).

“[... él las hacia las tronaduras... sí, el tenía su permiso, como él siempre fue pirquinero, tenía su permiso y él hacía las tronaduras (Cornelio Araya, 2013).

La mina Victoria, de hecho, cuenta con varias estructuras arquitectónicas que pueden haber albergado un número significativo de trabajadores, aunque muchos menos de los que residían en Crisanta. El sector residencial incluye áreas diferenciadas de habitación, cocina y baño, e incluso una estructura que podría haber sido ocupada por el/ los administradores pues se encuentra separada del resto. En términos del volumen de extracción de mineral es un asentamiento de envergadura "grande", pues además de las áreas de extracción directamente asociadas, parece haber acopiado el material proveniente de varios "puntos de extracción" cercanos, pero sin asentamiento visible. Destaca la existencia de un compresor marca General Motors y un motor de combustión interna que, junto con el camión/molino de 4 pistones grabado en el recuerdo, ejemplifican los medios tecnológico-productivos que Aguilar poseía, pero que, además, manipulaba.

Con todo, pareciera que Aguilar es quien más se acercó a la figura de lo que previamente fue don Modesto Escalante, un empresario residente en San Pedro de Atacama con un capital notoriamente mayor que el de

151, $\left.\mathrm{n}^{\circ} 35\right)$. También aparece como co-propietario en la manifestación de Nueva Esperanza de 1960, junto a Marcos Olivos Cora y Rodolfo del Carmen Olivos (FCBR, vol. 88, n 42 ), y de la mina Águila junto a Luis Aguilar Silva y Juan Copa Cruz en 1978 (FCBR, vol. 182, n 4 ). sus pares, aun cuando ambos participaron de parte del proceso productivo de la sal. No obstante, todo indica que Aguilar le vendía el grueso de su producción a Tomic, al igual que otra cantidad importante de pequeños mineros que coexistían en la época. En ese sentido, y contrariamente a Modesto Escalante, eran parte del proceso capitalista de la sal, pero nunca lo controlaron. En todo caso, algo interesante de notar es que tanto Gabino Aguilar, así como otros sampedrinos, se autodefinían y son reconocidos por otros habitantes locales como mineros/pirquineros "de siempre".

Varios de los campamentos que clasificamos como "exploratorios" o "pequeños" bien podrían corresponder a las explotaciones de estos pirquineros autónomos que funcionaron con un tipo de tecnología más rudimentaria e inversión de energía mucho menor, a nivel familiar. También es factible que muchos de ellos ni siquiera hayan inscrito sus explotaciones como pertenencias, cuestión que podría explicar que varios de los campamentos que identificamos no aparezcan en los registros documentales, siendo explotados "a la mala", tal como ocurre con muchos mineros artesanales indígenas (Yáñez y Molina 2008). Al no tener suficiente capital para transformarse en empresarios solventes, la vida de pirquinero era una alternativa insegura, pero que les permitía mantener su autonomía evitando someterse a las restricciones que supone la vida de un empleado asalariado.

\section{El palimpsesto de (trabajar y vivir en) las minas de sal}

Los restos materiales que han perdurado en los asentamientos registrados arqueológicamente, han sido vitales para comprender ciertos matices de la vida en las minas de sal, especialmente considerando que el registro documental y la historia oral ofrecen datos incompletos y muchas veces ambiguos. Un primer nivel de análisis tiene que ver con la cronología.

Resulta interesante que la temporalidad diferenciada que expresan las manifestaciones de yacimientos de sal, también es observable a partir de los restos culturales. La información de materiales vítreos indica que al menos en tres de los asentamientos -Fausto, Victoria y Crisantaaparecen consistentemente botellas con características tecnológicas que aluden a modalidades de producción 


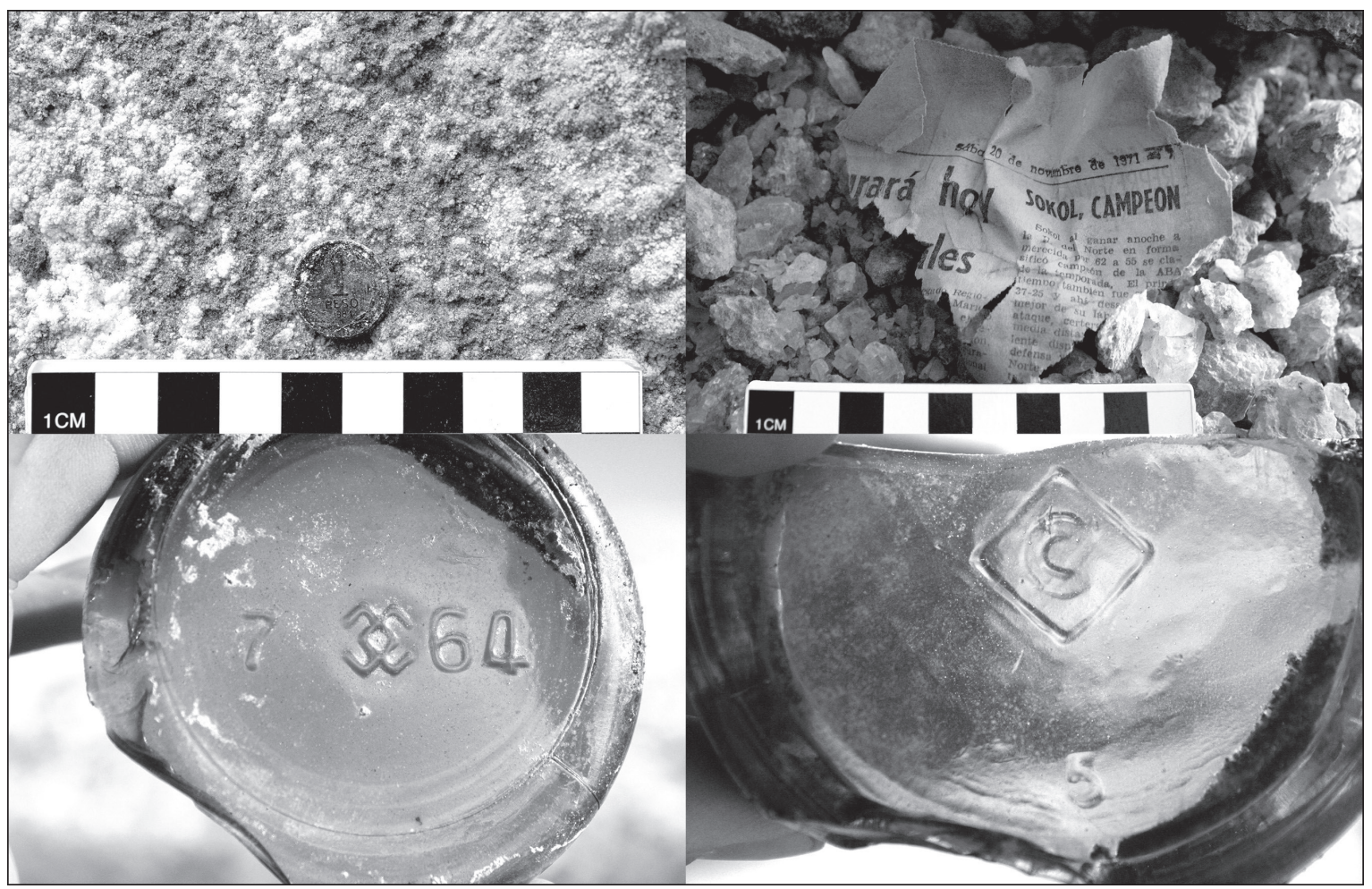

Figura 6. Materiales asociados a fechas. Arriba: moneda de 1981 (izquierda), fragmento de diario año 1971 (derecha). Abajo: base de botella Cristalería Chile año 1964 (izquierda), base de botella Chattanooga Glass Co., ca. 1901-1913 (derecha).

vigentes en el siglo XIX y principios del XX ("applied finish" 1830-1885; "cup mold" 1880-1910; "tooled finish" 1880-1910, molde de dos piezas 1850-1900; soplado y girado en molde 1880-1910), y de sellos de industrias vidrieras como Fábrica Nacional de Vidrios (ca. 19021929), Chattanooga Glass Co. (ca. 1901-1913) y Hemingray Glass Co. (ca. 1924- 1935) (Lorca 2014). Por otro lado, los vidrios de factura industrial de la segunda mitad del siglo XX, son mayoritarios en todos los sitios registrados -incluyendo aquellos sitios con indicadores más antiguos-, presentando sellos y estilos iconográficos que remiten a las décadas de 1960, 1970 y 1980, lo que está en concordancia con las fechas registradas en monedas (1966-1984) (Araneda 2013), loza (1963) (Baudet 2013) y un fragmento de diario El Mercurio con fecha 20 de noviembre de 1971 (Figura 6).

De acuerdo a lo anterior, es probable que los asentamientos que registramos tengan distintas temporalidades y/o historias de vida. Las explotaciones más tempranas deben haber sido análogas a aquellas que identificamos como "exploratorias", alcanzando proporciones mayores en momentos más tardíos. No obstante lo anterior, el registro material indica que las "exploraciones" siguieron realizándose ya entrada la década del 80 , tal como lo demuestran las zapatillas marca Bata registradas en el sitio homónimo. No existe, por lo tanto, una relación necesariamente evolutiva entre cronología y grado de complejidad de los asentamientos, cuestión que a la vez se traduce en la coexistencia de diferentes condiciones de vida y trabajo en un mismo tiempo, agregando un segundo nivel de análisis.

La evidencia arqueológica demuestra, por ejemplo, la existencia de restos de vestuario de seguridad asociada a los campamentos de mayor envergadura (Crisanta, La Micro, Tomic, Hondonada), no así para aquellos de menor escala productiva. Podríamos suponer que así como la empresa provee a los mineros de alimentación y alojamiento, también les proporciona elementos que 
resguarden su seguridad y que, en definitiva, promuevan un rendimiento más eficiente del negocio. Los pequeños pirquineros, en cambio, estarían a merced de sus posibilidades para procurarse ellos mismos dichos elementos. En lo que concierne a la alimentación, se recuerda la presencia de mujeres cumpliendo el rol de cocineras en aquellas minas explotadas por más de un trabajador. Se destacan diferencias de estilo de vida conforme trabajaran como empleadas de una mina, o de forma autónoma. En el primer caso, estaba mediado por una relación laboral, en la cual la administración le proporcionaba mercadería para que cocinara y se le pagaba por dicho servicio. En el segundo, por el contrario, la mujer cocinaba para su esposo y un socio en una mina pequeña, estando mediados por una relación de parentesco, por lo que ellos mismos debían proveerse de víveres en el almacén del pueblo. La base alimenticia era la misma en ambos casos: granos (porotos, frangollo, mote, lentejas, pataska) y en menor medida carne, pescado en conservas y frutos de estación, lo que es refrendado por la evidencia arqueológica (p. ej., mazorcas de maíz, cuesco de aceituna, de durazno, abundantes latas de pescado y mariscos), aunque de manera desigual dependiendo de la envergadura de los asentamientos. Sin embargo, los restos faunísticos aportan algunas precisiones.

Los restos de animales más populares corresponden a bóvidos y capríneos (Santander 2014). Los primeros están mayoritariamente representados por partes poco apetecidas en términos culinarios -a menos que constituyan un aporte a sopas a través de su médula (falanges, metapodios, carpo/tarso, etc.)-, a excepción de sitios más grandes como Crisanta, Fausto y Victoria donde se observan presas económicamente más importantes. Los capríneos, en cambio, aparecen con una mayor representación anatómica (Hondonada, Gutiérrez). En ese sentido, si entendemos los sitios como áreas preferentemente de consumo y no de producción de carne, parece plausible una crianza local de cabras o chivos en contraste a un ingreso ya procesado de vacunos. Esta información es relevante pues indica que posiblemente hubo un pequeño espacio para la mantención de animales menores, lo cual resultaría más factible en asentamientos medianos a pequeños a cargo de una unidad familiar, donde la mujer puede cumplir varios roles aparte de cocinar y donde el contexto es más permisivo en general. No obstante, esos datos de- ben ser acompañados de evidencias complementarias como guano y estructuras de corrales, que hasta ahora no han sido detectadas.

Además de las distinciones en formas de vida y trabajo, vale la pena detenerse en ciertos elementos transversales a los sitios, independientemente de su temporalidad y envergadura de explotación. Tal vez el que más llama la atención es el de la higiene y cuidado personal. Aun tratándose de un medio eminentemente masculino, existe una cantidad importante de peinetas, máquinas de afeitar (de metal y plástico) y pasta de diente que reflejan hábitos de limpieza bien establecidos. También aparecen artículos asociados al uso femenino, aunque corresponden a hallazgos particulares en sitios diferentes: un frasco de esmalte de uñas (Tomic) y un contenedor de porcelana de crema Pond's (Fausto) (Figura 7). Si bien la presencia de la mujer es minoritaria, es interesante que pese a cumplir roles en un medio físicamente rudo, mantengan prácticas de cuidado personal e incluso, coquetería. Con todo, es destacable que estos nuevos hábitos y su materialidad dan cuenta, finalmente, de la inserción de un oasis como San Pedro de Atacama, en un mundo no sólo moderno sino que cada vez más globalizado.

\section{Tensiones entre el Estado, la propiedad privada y el derecho ancestral sobre la tierra}

Desde la historia oral, la propiedad formal sobre el territorio presenta distinciones entre los habitantes del salar de Atacama, y quienes no son originarios del poblado de San Pedro de Atacama. Estos últimos son hasta el día de hoy conceptualizados como 'afuerinos'. Dentro de esta lógica, los dueños 'naturales' de las Salinas serían los habitantes originarios de la localidad, quienes usaban y ocupaban el territorio por derecho consuetudinario, incluyendo la extracción de recursos de su entorno. En ese sentido, por más que desde la arqueología se registren explotaciones de sal dentro de una lógica minera -e incluso capitalista-, no es seguro que se la tratase como un recurso mineral desde un principio, sino más bien en relación a sus cualidades para la nutrición, medicina y catalización de energías.

"[...] antes de que se instalaran campamentos mineros, los primeros pirquineros podríamos decir así, ellos llegaban con mula al sector, ellos con capacho y alforjas, ellos traían la sal desde el valle 


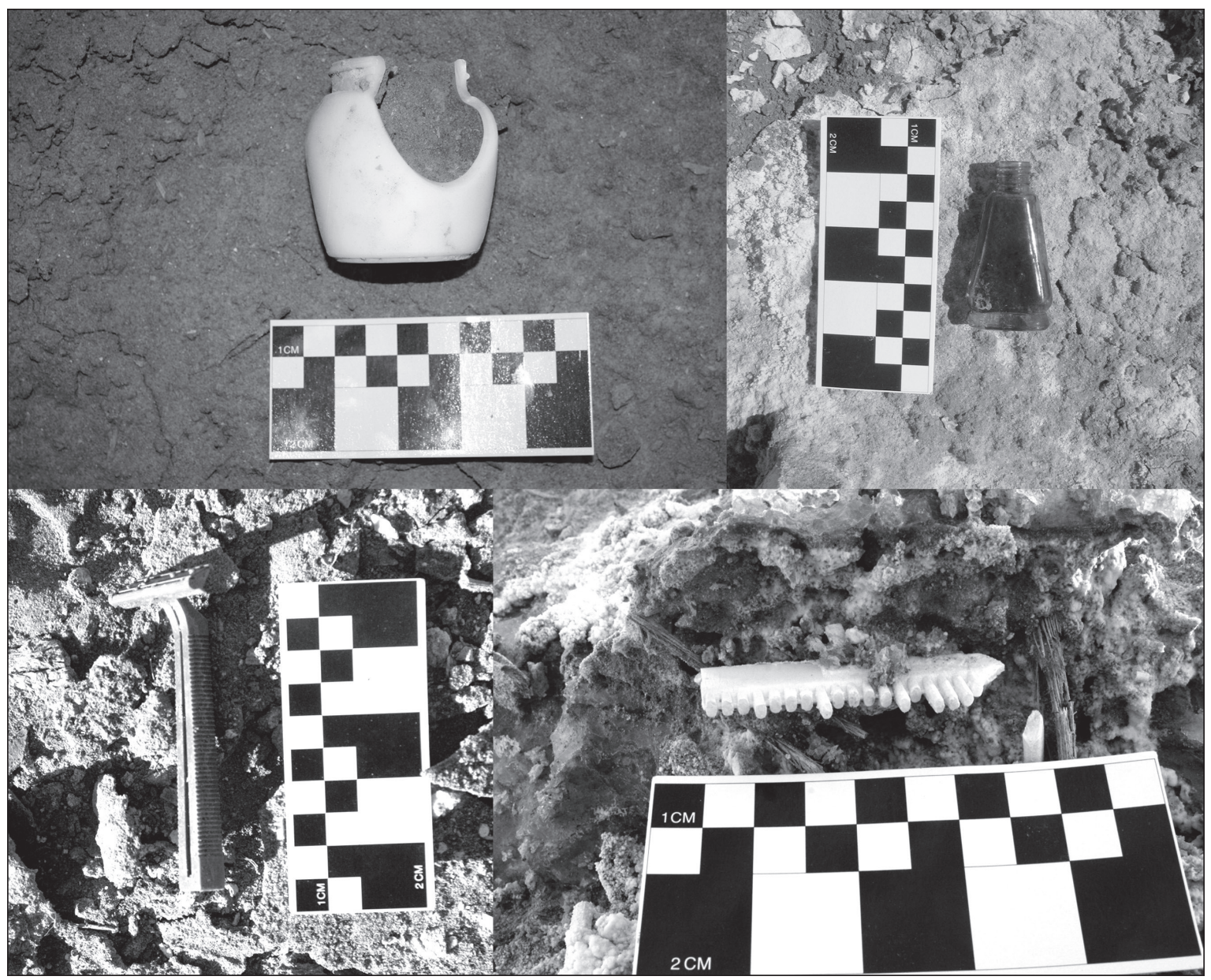

Figura 7. Materiales de aseo y cuidado personal. Arriba: frasco de crema Pond's (izquierda), frasco de esmalte de uñas (derecha). Abajo: afeitadora desechable (izquierda), peineta de plástico (derecha).

en las mulas, burros, caballos, [...] en aquellos tiempos cuando la sal era escasa eh..., entonces venía un caballero con una cuña y se apaleaba la veta, le sacaba pedacitos de piedra [...] todo eso se llama paltoquiar, chapalear, el mismo nombre tiene" (Eduardo Gómez, 2006).

"[...] en cada campamento minero existía siempre su yatiri o chamán y él siempre tenía contacto con la naturaleza, posteriormente a todas esas personas les llamaban los cateadores también [...] Ellos identificaban la veta con sólo mirar, hay unos que yo recuerdo que después de hacer el pago a la tierra, se quedaban coqueando y conversando con ella [...], en todo campamento minero existen siempre cosas anómalas, entonces que es lo que pasaba que siempre había visitas de yatiris al lugar porque quizás la energía acumulada que había en el sector era bastante [...] me recuerdo que decían que había que sacar la sal de noche porque estaba impregnada de toda esa energía..." (Fermín Bautista, 2006).

En la temporalidad ambigua de la memoria episódica de la gente de Atacama, la extracción de sal supone un acto sagrado a cargo de un especialista -el yatiri- para poder llevarse algo de la tierra mediante "pagos" ritualizados y en concordancia con una concepción personalista de ella. No obstante, el relato no deja claridad en cuanto a si ese sentido de pertenencia de la sal y la tierra, se mantuvo a lo largo del tiempo, una vez que se adoptó la lógica de explotación capitalista, manifestada no sólo en la aplicación de nuevas tecnologías y conocimiento en la extracción de la sal, sino en la inscripción de manifestaciones 
donde ya no sólo se "paga" a la tierra sino al Estado. Al menos contamos con testimonios en los cuales se afirma que capitalistas locales, como el propio Gabino Aguilar, mantenían prácticas tradicionales puesto que la misma tierra daba señales de requerir la restauración de cierto orden básico:

“[...] pasaban algunas cosas acá así anormales, pero mi papá [Gabino Aguilar] como él era una persona especial, espiritual, era chamán acá en San Pedro, acá en este lugar [mina Victoria] nunca tuvimos problemas. Creo que en las Tres Marías [mina Gutiérrez] hubo aloo ahí, pero junto con el padre Le Paige y mi padre se hicieron un pago a la tierra y todo pa' terminar con esas cosas" (Luis Aguilar, 2006).

En ese sentido, pareciera que al menos los habitantes originarios son capaces de incorporar fluidamente prácticas tradicionales al nuevo contexto económico. En otras palabras, la explotación de sal como recurso de una minería capitalista convive con una relación sacralizada con la tierra. En estos términos, es posible que el conocimiento local sea utilizado como un instrumento para asegurar la acumulación capitalista. En contraste, los indígenas aseguran la producción mediante herramientas rituales que invocan el permiso y bendiciones de la madre tierra durante la extracción; en ambos casos, el foco de atención es el mismo: la sal. Desconocemos, sin embargo, si es que Tomic en su abierta calidad de afuerino, permitía que sus empleados de raigambre indígena efectuaran "pagos" a la tierra dentro de sus jornadas de trabajo. O si, de prohibirlos, los mineros locales realizaban este tipo de prácticas de todas formas. Lamentablemente, se trata de prácticas difíciles de pesquisar en el registro arqueológico y que, además, es necesario analizar en el contexto del proceso de evangelización que se fue paralelamente desarrollando en la zona con figuras como los sacerdotes Domingo Atienza y Gustavo Le Paige, en la primera y segunda mitad del siglo XX, respectivamente.

En definitiva, podríamos pensar que, más allá de quién inscriba la pertenencia minera (afuerino/atacameño) o cuáles sean sus fines (tradicionales/mineros-capitalistas), es el Estado el principal afuerino, toda vez que incentiva la privatización de la tierra y sus recursos, cuestión que no es parte de la lógica local de relacionarse con ella, aun cuando haya sido incorporada por gran parte de los mineros locales. Esa autoridad del Estado sobre la propiedad de la tierra se acentúa a partir del gobierno militar, en 1973, afectando principalmente a los pirquineros y a los capitalistas más pequeños (Yáñez y Molina 2008). Por un lado, la dictadura implementó la Doctrina de Seguridad Nacional prohibiendo la tenencia y consecuente uso de explosivos. Las explotaciones medianas a grandes, y especialmente la gran mina Crisanta, debieron tener permisos para la adquisición de explosivos. Estos sitios, de hecho, presentan basuras arqueológicas propias de los años $80^{\prime}$ como zapatillas North Star, maquinillas desechables de afeitar marca Gillete, pisco Sotaquí y hasta una moneda de 1984, entre otros. No obstante, la evidencia arqueológica también indica que pirquineros solitarios siguieron trabajando clandestinamente en esa misma época, aunque con menor intensidad y frecuencia. Tal es el caso del sitio exploratorio donde se encuentran las mencionadas zapatillas Bata, cuyo modelo es propio de la década de 1980.

Por otro lado, a partir de 1978, los militares pusieron especial atención en la zona de Atacama por su importancia geopolítica, lo que se tradujo en la disposición de campos minados en varios sectores, incluyendo Seilao y Lampallar, al oeste del Valle de la Luna. No podemos dejar de mencionar el caso de don Juan Copa, antiguo minero de la sal ligado a las minas de don Gabino Aguilar, quien sufrió una grave lesión producto de la explosión de una mina antipersonal mientras buscaba leña. Si bien este hecho constituye el accidente más dramático y recordado por ex mineros locales, no tiene una incidencia directa en el fin de la explotación de la sal, que se produce a mediados de la década de 1980. La gran diferencia la marca la aparición de la empresa de sal "Punta de Lobos", con explotaciones de gran envergadura en el salar de Tarapacá, y que desde la década anterior comienza su expansión hacia nuevos mercados, incluyendo el exterior. Ni siquiera Tomic fue capaz de sobrevivir a dicha competencia, arrastrando consigo a la serie de empresarios menores que lo abastecían y que se vieron especialmente desprotegidos por un gobierno neoliberal volcado a la gran minería y el beneficio de la inversión extranjera (Yáñez y Molina 2008).

No deja de llamar la atención que en este nuevo contexto social, político y económico, se concrete la ocupación 
más patente del Estado chileno sobre el territorio de la Cordillera de la Sal, con la creación de la Reserva Nacional Los Flamencos en 1990, administrada por CONAF. Ello implicó la re-categorización de las Salinas pasando de ser una zona de explotación minera a un área protegida donde se prohíbe la extracción de sal y, por lo tanto, deja sin efecto las manifestaciones y derechos de propiedad inscritas hasta ese momento así como la explotación artesanal, que no aparece en los libros. ${ }^{21}$ Desde el año 2002 la administración del sector que incluye las Salinas es compartida con la Asociación Indígena Valle de la Luna, constituyéndose en una experiencia que ha sido reconocida como un logro de participación y autodeterminación indígena (Henríquez 2013), con tres objetivos centrales: la protección y conservación de la reserva, la recuperación y valorización de la cultura atacameña y la promoción del turismo (Seelau y Seelau 2012). No obstante, la co-administración no ha logrado superar el conflicto que subyace a la relación entre el Estado y las comunidades indígenas: el control jurídico de las tierras que conforman la reserva.

Las seis comunidades indígenas atacameñas que integran la Asociación Indígena Valle de la Luna, se han abocado al rescate de objetos, historias y lugares ligados a la extracción de sal, considerándola un emblema local del desarrollo minero de y en Atacama. ${ }^{22}$ Asimismo, quienes trabajan en la reserva atienden encargos de parientes y vecinos que les piden sal para mantener en buen estado de salud a sus animales, hacer artesanías o para consumo personal, dadas las cualidades otorgadas a la sal del lugar:

"[...] los guías de turismo dicen que se dejó de trabajar la sal porque no era lucrativa, pero fue porque el Estado chileno se la quitó a los atacameños [...] si esa sal es mucho mejor que la sal Lobos, que es sucia y no brilla como la sal gema, incluso es buena para los animales, le mata los bichos" (Humberto Reyes, 2013).

\footnotetext{
${ }^{21}$ La Reserva Nacional Los Flamencos fue creada el 17 de octubre de 1990 por Decreto Supremo 50 del Ministerio de Agricultura.

22 Proyecto FONDART “Las Salinas del Valle de la Luna”: DVD, exposición fotográfica in situ en mina Victoria. Circuito turístico histórico: minas Victoria, Gutiérrez y Crisanta. Esta última es parte de un proyecto actual de museo de sitio, dentro del cual se "reavivará" el campamento.
}

Se trata de un esfuerzo colectivo que cobra nitidez en la vida post mortem de las minas de sal como empresas capitalistas, pero que da cuenta de que las Salinas aún están vivas en una lógica culturalmente distinta que sigue resistiendo al Estado, aunque en tiempos igualmente capitalistas. En efecto, los nuevos usos de las Salinas, se dan en el contexto de la industria del turismo y a la luz de una diversidad de intereses y grupos de poder: científicos, recreativos, deportivos y culturales asociados al control de este espacio y sus recursos. El escenario visible, por lo tanto, es uno de control del territorio por parte de la Asociación Indígena. No obstante, evidencias de tensiones geo-administrativas e históricas con otras instituciones del Estado han sido enunciadas tras el análisis interdisciplinario de la evidencia arqueológica, histórica y antropológica que dan vida a este artículo.

\section{La minería de la sal en San Pedro de Atacama: un modelo mixto}

La retroalimentación entre las fuentes materiales, documentales y orales, nos ha permitido enriquecer los relatos derivados de cada una de ellas en miras a comprender el rol de la explotación de sal en San Pedro de Atacama, al alero del gran proceso capitalista industrial que arribó al país a fines del siglo XIX. Si bien aún no logramos precisar respuestas para cada una de las preguntas que nos hicimos inicialmente, estamos poco a poco identificando los pliegues de aquella topografía. $\mathrm{Al}$ otorgarle densidad a una serie de prácticas que ocurren en el seno de la vida material, éstas se van revelando cada vez más complejas.

En efecto, a diferencia de las primeras experiencias capitalistas en la localidad ligadas al comercio de ganado vacuno, y que permean con fuerza la memoria de los actuales habitantes de San Pedro, la explotación de las minas de sal se perfila como un fenómeno mucho más circunscrito y puntual, a pesar de ser una estrategia económica que estuvo en funcionamiento hasta tiempos muy recientes. Varios factores contribuyen a esto: las minas están cerca del oasis, pero la distribución de las vetas está acotada a la cordillera de la Sal, es decir fuera del territorio mismo de los ayllus; la industria de la sal involucró a un número importante de personas que no tenían residencia en San Pedro (empleados del empresario 
Tomic, especialmente); la cantidad de personas que trabajaba en las minas, excepto en Crisanta, era acotada; el procesamiento final de la sal ocurría mayoritariamente en Calama, al menos el de proporciones industriales; $y$ el impacto de esta industria nunca alcanzó niveles competitivos a nivel nacional, como sí lo tuvo la explotación de sal en el salar de Tarapacá.

Pese a que el capital sampedrino no logró incrementarse de manera significativa con respecto al tiempo de las remesas, se trata de un período en que Chile se vuelve un país más capitalista en general. El proyecto de industrialización nacional con respaldo estatal se inclinó cada vez más hacia la privatización. A escala local, podemos decir que se consolida el grupo de "productivistas independientes" (Salazary Pinto 1999), donde situamos a Esteban Tomic y Sucesión, Modesto Escalante e, incluso, a Gabino Aguilar. Junto a ellos se mantiene un grupo de mineros pirquineros que se resisten a emigrar hacia centros urbano-industriales e insisten en integrarse a la maquinaria capitalista local como proveedores, distribuidores o, sin más, empleados. En este contexto, concordamos con Pinto y Ortega (1990) en que la industrialización puede darse de forma limitada y especial, a partir de una serie de acomodaciones, en los instersticios del capitalismo. Así, vemos que en las Salinas del Valle de la Luna, el nivel más sofisticado de industrialización logra convivir con formas de explotación artesanal de un mismo recurso. Pese a las imposiciones del Estado, que no hacen sino ignorar la especificidad cultural del lugar, los habitantes del oasis se las han arreglado para mantenerse en un equilibrio precario, pero efectivo, entre ambos mundos.

Si bien el capitalismo no trajo a San Pedro la industrialización en su sentido más estricto, sí lo hizo partícipe de la globalización. Ello se traduce en un flujo permanente de productos e ideas que evidencian cómo San Pedro de Atacama, pese a ser un oasis, no se ha mantenido al margen de procesos económicos mayores. Prueba de ello es que en el ocaso de la explotación de la sal se funda una nueva y fuerte industria -la del turismo-, que le sigue dando vida a las Salinas.

Agradecimientos Este artículo es producto del Proyecto FONDECYT 1120087. Queremos agradecer a los integrantes de nuestro equipo Yerko Araneda, Daniela Baudet, Jimena Cruz, Jorge D'Orcy, Wilfredo Faúndes, Paula González, Marion Guinard, Jesús Inostroza, Ricardo Labra, Rodrigo Lorca, Alex Paredes, Francisco Rivera, Boris Santander, Cristhian Tapia y Mauricio Vargas, quienes contribuyeron en labores de terreno y/o en el análisis de material arqueológico, etnográfico o documental. Igualmente, agradecemos a la Asociación Indígena Valle de la Luna, quienes han facilitado nuestro trabajo en las Salinas, además de compartir información, recuerdos y experiencias sobre las mismas. Finalmente, toda nuestra gratitud a las comunidades de San Pedro de Atacama por compartir sus testimonios con nosotros.

\section{$*$ Referencias citadas}

\section{Fuentes documentales}

\section{Archivo Nacional de Chile}

- Fondo Intendencia de Antofagasta (FIA), vols. 1-66. Años 18791928.

- Fondo Conservadores de Bienes Raíces El Loa (Calama) (FCBR), vols. 1-190, años 1925-1981.

\section{Publicaciones}

ANÓNIMO. 1970. Tomic palabra de hombre. Folleto político, Santiago de Chile (?).
ARANEDA, Y. 2013. Informe de análisis de materiales metálicos, Proyecto FONDECYT 1120087, segundo año de ejecución (2013). Ms. en posesión del autor.

BAUDET, D. 2013. Informe de análisis de loza, Proyecto FONDECYT 1120087 , segundo año de ejecución (2013). Ms. en posesión del autor.

BUCHLI, V. 2000. An archaeology of socialism. Berg, London.

BUCHLI, V. y G. LUCAS. 2001. The absent present: archaeologies of the contemporary past. En Archaeologies of the Contemporary Past, Buchli y Gavin Lucas (Eds.), pp. 3-18. Routledge, London and New York. 
CÁRDENAS, U. 2006. Las Salinas del Valle de la Luna: Historia olvidada de un asentamiento minero contemporáneo en la Puna de Atacama, II Región de Antofagasta. Ms. en posesión del autor.

CARMAGNANI, M. 1998 [1971]. Desarrollo industrial y subdesarrollo económico. El caso chileno (1860-1920). DIBAM, Santiago de Chile.

CAVIERES, E. 1998. Industria, empresarios y Estado. Chile, 18801934 ¿Protoindustrialización o industrialización en la periferia? En Desarrollo industrial y subdesarrollo económico. El caso chileno (1860-1920), M. Carmagnani (Ed.), pp. 11-30. Dirección de Bibliotecas, Archivos y Museos, Santiago de Chile.

DE VOS, B. 1999. El surgimiento del paradigma industrializador en Chile (1875-1900). DIBAM, Santiago de Chile.

FOUCAULT, M. 1980. Microfisica del poder. Las Ediciones de La Piqueta, Madrid.

GONZÁLEZ, H. y V. GAVILÁN. 1990. Cultura e identidad étnica entre los aymaras chilenos. Chungara 24-25: 145-158.

GONZÁLEZ-RUIBAL, A. 2006. The past is tomorrow. Towards an archaeology of the vanishing present. Norwegian Archaeological Review 39(2): 110-125.

GONZÁLEZ-RUIBAL, A. 2007a. Making things public: archaeologies of the Spanish civil war. Public Archaeology 6(4): 203226.

GONZÁLEZ-RUIBAL, A. (Ed.), 2007b. Arqueología simétrica: Un giro teórico sin revolución paradigmática. Complutum 18: 283319.

HARRISON, R. y J. SCHOFIELD. 2010. After Modernity. Archaeolgoical approaches to the contemporary past. Oxford University Press, Oxford y New York.

HENRÍQUEZ, A. 2013. Participación indígena: desarrollo y alcances en torno a la participación ambiental. Lus et Praxis 19(2): 251300.

HOLTORF, C. y A. PICCINI (eds.), 2011. Contemporary archaeologies. Excavating now. Peter Lang, Frankfurt am Main.

JOHNSON, M. 1996. An archaeology of capitalism. Blackwell, London.

JURADO, C. 2013. Doble domicilio: Relaciones sociales y complementariedad ecológica en el norte de Potosí (Bolivia), del temprano siglo XVII. Chungara 45(4): 613-630.
LEONE, M. 1985.A historical archaeology of capitalism. American Anthropologist 97(2): 251-268.

LEONE, M. 1999. Setting some terms for historical archaeologies of capitalism. En Historical Archaeologies of Capitalism, M. Leone y P. Potter (Eds.), pp. 3-10. Plenum Publishers, New York.

LORCA, R. 2013. Análisis de materiales vítreos. Proyecto FONDECYT 1120087 , segundo año de ejecución (2013). Ms. en posesión del autor.

MATAIC, D. 1998. Croatas en Chile. Biografias. CIP - Katalogizacija u publikaciji Nacionalna i sveucilisnaknjiinica, Zagreb.

MESKELL, L. 2004. Object worlds in ancient Egypt: material biographies past and present. Berg, Oxford.

NÚÑEZ, L. 2007 [1991]. Vida y cultura en el oasis de San Pedro de Atacama. Editorial Universitaria, Santiago de Chile.

ORTEGA, L. 1991-1992. El proceso de industrialización en Chile 1850-1930. Historia 26: 213-246.

PINTO, J. y L. ORTEGA. 1990. Expansión minera y desarrollo industrial: un caso de crecimiento asociado (Chile 1850-1914). Departamento de Historia, Universidad de Santiago de Chile, Santiago de Chile.

SALAZAR, G. y J. PINTO. 1999. Historia contemporánea de Chile II. Actores, identidad y movimiento. LOM ediciones, Santiago de Chile.

SANHUEZA, C. 2012. La tradición arriera de Atacama (siglo XIX). En Atacama, C. Aldunate (Ed.). Museo Chileno de Arte Precolombino, Santiago de Chile.

SANHUEZA, C. y H. GUNDERMANN. 2007. Capitales, Estado rentista y cambio social atacameño en las regiones interiores de Antofagasta (1879-1928). Estudios Atacameños 34: 113-136.

SANTANDER, B. 2014. Análisis de restos óseos de los oasis de San Pedro de Atacama a través de registro fotográfico, Proyecto FONDECYT 1120087 , segundo año de ejecución (2013). Ms. en posesión del autor.

SEELAU, L. y R. SEELAU. 2012. Protegiendo sus territorios: coadministración entre comunidades atacameñas y el Estado chileno en el Valle de la Luna. En Defensa de los derechos territoriales en América, M. Fernández y J. Salinas (Eds.). RIL Editores, Santiago de Chile.

VILCHES, F. 2011. From nitrate town to internment camp: the cultural biography of Chacabuco, Northern Chile. Journal of Material Culture 16(3): 1-23. 
VILCHES, F., L. SANHUEZA y C. GARRIDO. 2014. Patrimonio (in)visible: arquitectura de remeseros en San Pedro de Atacama. $A R Q 88$ (en prensa).

WITMORE, C. 2007a. Arqueología simétrica: un manifiesto breve. Complutum 18: 305-312.

WITMORE, C. 2007b. Landscape, time, topology: An account of the southern Argolid Greece. En Landscapes in Archaeology, D. Hicks, G. Fairclough y L. McAtackney (Eds.), pp. 194-225. Routledge, London.
YÁÑEZ, N. y R. MOLINA. 2008. La gran minería y los pueblos indígenas en el norte de Chile. LOM ediciones, Santiago de Chile.

ZLATAR, V. 2002. Inmigración croata en Antofagasta. Oñate Impresores, Antofagasta.

ZLATAR, V. y H. OSTOJIC. 2006. De la bura a la camanchaca. Historia de Povlja y de sus emigrantes al norte de Chile. Oñate Impresores, Antofagasta. 